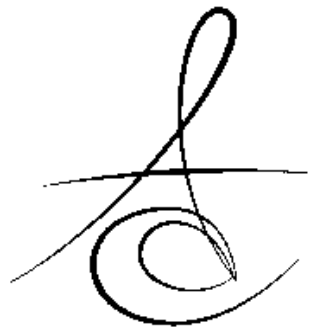

\title{
DİŞ HEKİMLİĞİNDE KULLANILAN BAZI BİTKİLERİN ANTİBAKTERİYAL VE ANTİFUNGAL ETKİLERİ
}

\section{SOME OF THE PLANTS USED IN DENTISTRY ANTIBACTERIAL AND ANTIFUNGAL EFFECTS}

Prof.Dr. Ertuğrul ERCAN*

Dt.Esra GÜLAL*

Makale Kodu/Article code: 1870

Makale Gönderilme tarihi: 26.09 .2014

Kabul Tarihi: 26.11.2014

\section{ÖZET}

Diş çürükleri, periodontal hastalıklar ve diş kaybı toplumun büyük bir kısmını etkileyen ağızda görülen hastalıklardır. Diş çürüğünü ve mantar enfeksiyonlarını engellemede tabiatta var olan kaynaklar önemli rol oynamaktadır. Bu derlemede diş hekimliğinde kullanılan bazı bitkilerin antibakteriyal ve antifungal etkilerini değerlendirilmiştir.

Diş çürüklerine karşı birçok antibakteriyal ürün geliştirilmesine rağmen henüz hala ideal bir antibakteriyal ajan mevcut değildir. Bu durum bitkilerin antibakteriyal etkisinin araştırılması için bir fikir oluşturmuştur. Bitkiler uzun yıllardan beri diş sağlığını korumak ve artırmak için kullanılmaktadır. Bu bağlamda antibakteriyal ve antifungal etkileri kanıtlanmış bitkiler bulunmaktadır.

Bu derlemede bitkilerin ağız sağlığı üzerindeki olumlu ve olumsuz etkilerinin yanısıra kimyasal yapıları ve kullanımları tartışılmaktadır.

Anahtar Kelimeler: Diş çürüğü, antibakteriyal etki, antifungal etki, misvak, mamey ağacı, çay ağacı yağı, neem ağacı

\section{GİRİş}

Ağız ve diş sağlığı genel sağlığın ayrılmaz bir parçasıdır. Ağız hastalıkları tüm dünyada yaygın olan bir sağlık problemidir., ${ }^{1,2}$ Dünya Sağlık Örgütü raporlarına göre diş çürüğü ve dişeti hastalıkları, yeryüzünde en yaygın görülen hastalıklar olarak kabul edilmektedir. Bu hastalıkların nedeni ise diş yüzeylerinde biriken bakteri ve bakterilerin artık ürünleri ile tükürük glikoproteinlerinden oluşan dental plaklardır. ${ }^{3}$ Kötü ağız hijyeni, bakteri ihtiva eden biyofilm oluşmasına neden olur. Biyofilm oldukça karmaşık bir yapıya sahiptir ve farklı türde birçok bakteri ihtiva etmektedir. ${ }^{4,5}$

\section{ABSTRACT}

Oral diseases, including dental caries, periodontal disease, and tooth loss, affect the majority of the population and can affect a person's overall health. Nature plays an important role as a source of new antibacterial and antifungal substances that can be used in the prevention of caries and fungal infection.

Many antibacterial agents have been developed against dental caries. However, they lack the qualities of an ideal agent. Thus presently, antibacterial activity of herbal agents is being extensively studied. Plants have been used for centuries to improve dental health and to promote oral hygiene. Antibacterial and antifungal effects of some plants have been proved as well.

This review discusses chemical composition and usage of these plants as well as their influence on oral health with pearls and pitfulls.

Keywords: Dental caries, antibacterial effect, antifungal effect, salvadora persica, mammea americana, tea tree oil, azadirachta indica

Ağız ortamı besinden zengin, $35-36 \mathrm{C}^{0}$ sıcaklık ve $6.75-7.25$ pH'a sahiptir. $^{6} \mathrm{Bu}$ şartlar birçok bakterinin ağız içerisinde muhtelif yerlerde biyofilm oluşturmasına olanak tanımaktadır. ${ }^{7}$ Dental plak olarak adlandırılan bu biyofilm ağızda en sık görülen diş çürüğü ve periodontal hastalıklar ile oldukça yakın ilişkilidir. Bu iki hastalık endüstrileşmiş toplumlarda toplumun büyük bir kısmında görülmektedir. Refah seviyesinin yüksek olması ve sağlık hizmetlerine erişilebilirlik önemli bir etkiye sahiptir. ${ }^{8}$

Diş çürüğü, multifaktöriyel bir hastalık olup, minenin demineralizasyonuyla karakterize bir hastalıktır. ${ }^{9}$ Karbonhidratın içerikli besinlerin sık tüketilmesi,

*Kırıkkale Üniversitesi, Diş Hekimliği Fakültesi, Restoratif Diş Tedavisi Anabilim Dalı

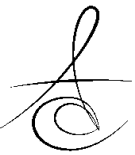


bu besinlerin bakteriler tarafından fermente edilmesi ve fermantasyon sonucu asit üretimi diş çürüğü oluşumu ile ilgili temel konulardır. ${ }^{6},{ }^{10},{ }^{11}$ Asidojenik (asitte üreyebilen) ve asidürik (asit ortamında yaşayabilen) özelliğe sahip S.mutans, S.sobrinus ve Lactobacillus gibi bakteriler minenin demineralize olacağı seviyelere $\mathrm{pH}^{\prime} ı$ düşürerek çürüğe neden olurlar ${ }^{12,13}$.

Streptokokus mutanslar ( $S$. mutans) diş yüzeyine yapışabilme ve ekstraselüler polisakkarit oluşturma yeteneğine sahiptir. ${ }^{14} \mathrm{Bu}$ özelliği ile diğer bakterilerden ayrılmaktadır. ${ }^{15}$ Suda çözünmeyen ekstraselüler dekstranlar üretip, bakterilerin diş yüzeyine yapışmasını sağlamaktadır. ${ }^{16}$ Öte yandan, karbonhidrat rezervi olarak görev yapan intrasellüler polisakkarit sentezi de yapabildiği belirtilmiştir. ${ }^{17}$ Streptokokus, Laktobasillus, Aktinomiçes ve P.gingivalis çürükten ve diş eti hastalıklarından en çok sorumlu tutulan bakterilerdir. ${ }^{18}$

Oral patojenlerden korunmak için antimikrobiyal ve antibakteriyel ajanlar araştırılmış, klorheksidin, povidon-iodin, delmopinol hydrochloride, triclosan diş hekimliğinde kullanıma sunulmuştur. ${ }^{19}$ Ancak bu ajanlarda istenmeyen yan etkilerin bakım ağız hijyeni için tıbbi bitkilerin kullanımı yaygın bir ilgi duyulmaktadır. Bu bağlamda geleneksel bitkisel tıp da araştırma kapsamına girmiştir. ${ }^{20} \mathrm{Bu}$ bitkinin yararlı etkilerini anlatan çeşitli raporlar vardır; bu ağız boşluğu patojenik mikroorganizmaların düşürülmesi ve diş çürümelerine karşı yeteneğine sahip olduğu gösterilmiştir. ${ }^{21-23} \mathrm{Bu}$ derlemede geçmişten günümüze kadar kullanılıp etkisi kanıtlanan bitkiler antibakteriyal ve antifungal özellikleri ile ele alınmaktadır.

\section{Antibakteriyel Özellikler \\ 1.1Salvadora Persika(Misvak)}

Salvadora Persika, halk arasında erak ağacı olarak bilinen bir bitkinin kök ve dallarından elde edilen bir fırçadan (misvak) ağız ve diş temizliğinde önemli bir yer tutmaktadır. ${ }^{24}$ S.persika, Salvadoraceae ailesinden arak ağacının botanik adıdır. ${ }^{25}$ Yumuşak beyazımsı sarı ahşap küçük bir ağaç olup Afrika, Güney Amerika'da Orta Doğu ve Asya geleneksel olarak ağız temizliğinde kullanılmaktadır. ${ }^{22} \mathrm{~S}$. persica ekstrakları anticaries, $^{26}$ antiperiopathic ${ }^{27}$, antibakteriyal ${ }^{28}$ ve antifungal $^{29}$ antiplasmodial $^{30}$ etkileri göstermektedir. ${ }^{31}$ Doğu Afrika'dan Hindistan'a kadar olan bölgelerde yetişen bu step bitkisi bol, ekonomik ve pratiktir. ${ }^{32}$ Misvakı tıbbi bakımda, kimyevi yönüyle selüloz elyafı ve uçucu yağlar, kokulu bir reçine ve madeni tuzlar ihtiva etmektedir. Bazı araştırmacılar, bu bitki içinde klorür, kalsiyum, florür, silika, bir sülfür bileşiği, C vitamini, taninler, saponinler, reçineler, fitosteroller, flavonoidler, triterpenler ve alkaloidler önemli bir miktarda olduğunu bildirmiştir. ${ }^{23,} 33$ Burada yüksek klorid içerikli izotiyosiyanat bileşeni ağız mikroflorasına büyümesini inhibe edebilir, diş taşı oluşumunu azaltmakta ve dişlerin lekelenmesini önlemekte olduğu düşünülmektedir. ${ }^{33}$

Almas ve ark., ${ }^{34}$ yaptıkları bir çalışmada $\mathrm{S}$. persika ekstraktının, S.mutans ve E.faecalis üzerinde antibakteriyel etkisinin olduğunu ifade etmektelerdir. Bakterinin dişe yapışmasının engellenerek bu etkinin ortaya çıktığını düşünmüşlerdir. Aynı zamanda kökü ve gövdesi arasında antibakteriyal etkinlik açısından farklılık olduğunu tespit etmişlerdir. ${ }^{34}$

Darout ve ark., ${ }^{13}$ salvodare persika'nın tükürükteki peroksidaz tiyosiyonat ve hidrojen peroksidaz antibakteriyel sistemlerini aktive ederek etkili olduğu hipotezini savunmuştur ve S.persica kullanan bireylerde S.mutans seviyesinin, diş fırçası kullananlarda ise periodontal patojenlerin daha düşük seviyede bulunduğunu tespit etmiştir. ${ }^{13}$ Farooqi ve ark, S.persica'nın kimyasal bir bileşeni olan BITC(benzil izo tiyosiyonat)'ın bakterilerin gelişimi esnasında inhibitör görevi üstlenerek antibakteriyal etki gösterdiğini bulmuştur. ${ }^{14}$ Bazı in vitro çalışmalar S. Persica, Candida albicans gibi çeşitli oral aerobik ve anaerobik gibi bakterilerin üremesini inhibe ettiğini göstermiştir. ${ }^{28,29}$

\subsection{MAMEY AĞACI (Mammea americana)}

$\mathrm{Bu}$ ağaç yapraklarını dökmeyen, güney Amerika'da yetişen ve yaprağı, çiçeği, meyvesi tedavi edici amaçı kullanılan bir bitkidir. Antikonvülzan, antipiretik, antimalaryal ve deri parazitleri için tonik olarak kullanılmaktadır. ${ }^{35}$

Herrera ve ark., ${ }^{36}$ yaptıkları çalışmada M.americana çekirdeğinin S.mutans ve P.gingivalis üzerinde antibakteriyal etkinlik gösterdiğini saptamıştır. ${ }^{36} \mathrm{Bu}$ bitki ile diş hekimliği alanında yapılan çalışma sayısı oldukça sınırlıdır ve üzerinde daha fazla çalışma yapılmalıdır.

\section{3 ÇAY}

Çay oldukça yaygın olarak kullanılan bir bitkidir. İran'da yapılan bir çalışmada yeşil ve siyah çayın s.mutans üzerinde antibakteriyal etkinliğe sahip olduğunu, bu etkinin siyah çayda daha düşük konsantrasyonlarda görüldüğünü rapor etmişlerdir. ${ }^{37}$ Çayın antibakteriyal etkisinin kimyasal içeriğindeki polifenol, kateşin, gallik asit ve flavinlerden kaynaklandığı düşünülmektedir. ${ }^{38}$ Linke ve ark. $^{39}$ çalışmalarında 
diyetteki şeker tüketimine bağlı oluşabilecek diş çürüklerini siyah çayın azalttığı sonucunu bulmuşlardır. Çayda bulunan kateşinlerden olan EGCG (Epigallocatechin -3 gallate) halitozisin temel sebeplerinden olan metil merkaptanın kokusunu giderir. ${ }^{40}$ Yine EGCG, P.gingivalis'in bukkal epitel hücrelere adezyonunu ve gelişimini engellediği yapılan çalışmalarda tespit edilmiştir. ${ }^{41}$

\section{4 ÇAY AĞACI YAĞI(TEA TREE OİL)}

Saxer ve ark, çay ağacı yağı kimyasal bileşenleinden olan 1,8-cineole ve terpinen-4-ol sayesinde ağızdaki enflamasyon bulgularının azaldığını görmüşlerdir. ${ }^{42}$ Takarada ve ark, bu bitkinin S.mutans ve P.gingivalis'in dişe adezyonunu engellediğini çalışmalarında ortaya koymuşlardır. ${ }^{43}$ Çay ağacı yağı, bakterinin membran geçirgenliğini bozarak lizise neden olur, bu da bakteri içine iyon girmesine ve akabinde de metabolik aktvitenin bozulmasına neden olduğu yapıIan çalışmalarda gösterilmiştir. ${ }^{44}$ Çay ağacı antibakteriyal ve antifungal etkinliğinden dolayı bazı macunlarda kullanılmaktadır.

\subsection{NEEM AĞACI (Azadirachta indica)}

$\mathrm{Bu}$ konuda yapılan çalışmalar, neem ekstraktının S.mutans'a karşı antibakteriyal etkinlik gösterdiğini ve bu etkinin $\% 50$ 'lik konsantrasyonda maximum seviyede görüldüğünü ortaya koymaktadır. ${ }^{45}$ Kimyasal bileşiminde alkaloid, glikozid, trepenoid, steroid ve tannin bulunmaktadır. ${ }^{46}$ Neem ekstraktı, periodontal ligamentte bulunan fibroblastlar ile yüksek biyouyum göstermesi sebebi ile periodontal hastaIıkların tedavisinde oldukça etkili bir biçimde kullanımasının en önemli sebebidir. ${ }^{47}$ İçeriğindeki gallotannin, bakterinin glukan üretimini ve kümelenmesini engellemektedir. ${ }^{48}$ Neem ağacından elde edilen kanal irrigasyon solüsyonun e.faecalis'in dentin dokusuna adezyonunu engellediği yapılan çalışmada tespit edilmiştir. ${ }^{49}$

\section{Antifungal Etkiler}

\subsection{SALVADORA PERSİCA(MİSVAK):}

Bagieh ve ark, yaptıkları çalışmada S.persica'nın kimyasal içeriğindeki yüksek sülfat içeriğine bağlı olarak Candida Albicans üzerinde antifungal etkiye sahip olduğunu bulmuştur. ${ }^{29} \mathrm{Al}-$ Bayati ve Sulaiman'ın yaptıkları çalışmada S.persica'nın sulu ve metanollü ekstraktlarının C.albicans da dahil olmak üzere oral patojenler üzerindeki etkisine bakılmıştır. S.persica'nın sulu ekstraktı L. acidophilus ve P. Aeruginosa'da, metanollü ekstraktı E.faecalis de daha güçlü antibakteriyal etkiye sahipken, Candida Albicans üzerinde sulu ve metanollü ekstraktlar aynı derecede antifungal etki göstermiştir. ${ }^{50}$ Noumi ve ark. ise kuru ve taze misvağın antifungal kapasitelerini agar difüzyon yöntemi ile değerlendirdikleri bir çalışma da kuru misvağın taze misvağa göre daha yüksek antifungal etkinlik gösterdiğini bulmuşlardır. ${ }^{51}$

\subsection{MAMEY AĞACI(Mammea americana)}

Mamey ağacı'nın antifungal etkinliği yada kapasitesi ile ilgili literatürde henüz yapılmış bir çalışma bulunmamaktadır.

\section{3 ÇAY}

Çayda kateşinlerden olan EGCG'nin Trichophyto mentagrophytese, T.rubrum'a, Cryptococcus neoformans'a ve C. Albicans'a karşı antifungal etkisi bulunmuştur. ${ }^{52}$ Farklı bir çalışmada ise EGCG'nin düşük konsantrasyonlarda $\left(2.5 \mathrm{mg} \mathrm{mL}^{-1}\right) \quad$ C. albicans ve C. eoformans'a antifungal etki göstermediği, Trichphyton ve $T$. Mentagrophytes'e ise onsantrasyon ve süreye bağlı olarak antifungal etki gösterdiği vurgulanmıştı. ${ }^{53}$ EGCG'ye farklı antifungal ajanların (amfoterisin b, flukonazol gibi) eklenmesi ile değişik mantar türlerinin sinerjistik etki oluşturmasını engellediği görülmüştür. ${ }^{54}$ In vitro bir çalışmada EGCG ve yine çayın kimyasal içeriğinde bulunan polifenollerin c.albicans'da metabolik dengesizliğe neden olduğu görülmüştür. ${ }^{55}$

\section{4 ÇAY AĞACI YAĞI(TEA TREE OİL)}

Shao ve ark., yaptığı bir çalışmada çay ağacı yağı antifungal etkisini; öncelikli olarak TTO hücre duvarını harap ediyor, membran yağ asitlerinin bileşiminin değiştiriyor, bu da membran geçirgenliğini ve hücresel materyallerin salınımını artıııyor. ${ }^{56}$

Terzi ve ark., yaptıkları bir çalışmada çay ağacı yağının kimyasal yapısındaki özellikle hangi maddelerin antifungal etkiye sahip olduğunu araştırmışıı. T-4-ol ve a-terpineol bu bağlamda en etkin iki kimyevi içerik olarak karşımıza çıkmaktadır. ${ }^{57}$ Aynı zamanda T-4-ol ve a-terpineol'un yapısındaki hidroksil grupları orta derecede suda çözünebilir olma özelliği kazandırmaktadır. Böylece bu maddeler su ile hücreye girer, hücre membranının stabilizasyonunu bozmaktadır ve olay akışı osmotik şok ile sonuçlanmaktadır. ${ }^{58}$ Dolayısıyla, antifungal etkinlik bu bitkide bu şekilde ortaya çıkmıştır. ${ }^{58}$

\subsection{NEEM AĞACI (Azadirachta indica)}

Azacdirachta indica; alkaloid, glikozid, saponin, flavonoid, steroid, antrakinon ve tannik asit intiva 
eder. $\mathrm{Bu}$ zengin içeriğin antifungal etkide oldukça önemli olduğu görülmüştür. Aynı zamanda etanolik ekstrakt sulu ekstrakta göre daha yüksek antifungal etkinlik gösterir. ${ }^{59,60}$ A.indica'nın farklı konsantrasyondaki sulu ekstraktları mantarlardaki miselyum gelişimini baskılar, bu da kimyasal etkinin artmış olarak algılanmasına neden olmaktadır. ${ }^{61}$

Birçok bitkinin oral patojenler üzerindeki etkisi hala incelenmemiştir. Bu yönde yapılacak çalışmalar ile yeni ve yüksek antimikrobiyal etkinliğe sahip, istenmeyen yan etkilerin ortan kalktığı antibakteriyal ve antifungal bitkilerin keşfine kapı aralayacaktır.

\section{KAYNAKLAR}

1. Simon C, Tesfaye F, Berhane Y. Assessment of the oral health status of school children in Addis Ababa. Ethiop Med J 2003;41:245-56.

2. Merchant AT. Periodontitis and dental caries occur together. J Evid Based Dent Pract 2012;12:18-9.

3. Harris $R$, Nicoll $A D$, Adair PM, Pine CM. Risk factors for dental caries in young children: a systematic review of the literature. Community dental health 2004;21:71-85.

4. McDonald RE AD, Stookey GK. . Dental caries in the child and adolescent. In: Dentistry for the Child and Adolescent, Ed.: McDonald RE, Avery DR, St.Louis: Mosby Inc,. 2000:209-46.

5. Milgrom $\mathrm{P}$ RC, Weinstein $\mathrm{P}$, Tanner ACR, Manibusan L, Bruss J. . Dental caries and its relationship to bacterial infection, hypoplasia, diet, and oral hygiene in 6- to 36-monthold children. Community Dent Oral Epidemiol 2000;28:295-306.

6. Marsh PD. Are dental diseases examples of ecological catastrophes? Microbiology 2003;149: 279-94.

7. Jenkinson HF, Lappin-Scott HM. Biofilms adhere to stay. Trends Microbiol 2001;9:9-10.

8. Petersen PE, Lennon MA. Effective use of fluorides for the prevention of dental caries in the 21st century: the WHO approach. Community Dent Oral Epidemiol 2004;32:319-21.

9. Selwitz RH, Ismail AI, Pitts NB. Dental caries. The Lancet 2007;369: 51-59.

10. Koçanalı B, Ak AT, Çoğulu D. Çocuklarda Diş Çürüğüne Neden Olan Faktörlerin İncelenmesi. Pediatric Research 2014;1:76-9.
11. Olmez S, Uzamis M, Erdem G. Association between early childhood caries and clinical, microbiological, oral hygiene and dietary variables in rural Turkish children. Turk J Pediatr 2003;45:231-36.

12. Beighton D, Al-Haboubi M, Mantzourani M, Gilbert SC, Clark D, Zoitopoulos L, et al. Oral Bifidobacteria: caries-associated bacteria in older adults. J Dent Res 2010;89:970-4.

13. Maden EA, Altun C. Probiyotikler ve Ağız Sağlığı. Atatürk Üniv Diş Hek Fak Derg 2012:334-39.

14. Kadriye $P$, Gülçin $B$. Erken Dönem Süt Dişi Çürüklerinin Önlenmesinde Risk Değerlendirmesinin Önemi. Atatürk Üniv Diş Hek Fak Derg 2013; 23:106-15.

15. Li X, Hoogenkamp MA, Ling J, Crielaard W, Deng DM. Diversity of Streptococcus mutans strains in bacterial interspecies interactions. J Basic Microbiol 2014;54:97-103.

16. Newburn E. Cariology. Quintessence Publishing Co. Inc. USA. 1989:63-89.

17. van Houte J. Role of micro-organisms in caries etiology. J Dent Res 1994;73:672-81.

18. Mannaa A, Carlen A, Campus G, Lingstrom P. Supragingival plaque microbial analysis in reflection to caries experience. BMC Oral Health 2013;13:5.

19. Ulusoy AT. Pedodontide Güncel Koruyucu Yaklaşimlar. Atatürk Üniv Diş Hek Fak Derg 2010:28-37.

20. Apatzidou DA. Modern approaches to non-surgical biofilm management. Front Oral Biol 2012;15:99116.

21. Almas K. The antimicrobial effects of extracts of Azadirachta indica (Neem) and Salvadora persica (Arak) chewing sticks. Indian journal of dental research: official publication of Indian Society for Dental Research 1998;10:23-26.

22. Almas K. The effect of Salvadora persica extract (miswak) and chlorhexidine gluconate on human dentin: a SEM study. J Contemp Dent Pract 2002;3:27-35.

23. Akhtar MS, Ajmal M. Significance of chewing-sticks (miswaks) in oral hygiene from a pharmacological view-point. J Pak Med Assoc 1981;31:89.

24. Balto HA, Al-Manei KK, Bin-Mohareb TM, Shakoor ZA, Al-Hadlaq SM. Cytotoxic effect of Salvadora persica extracts on human gingival fibroblast cells. Saudi Med J 2014;35:810-5. 
25. Darout IA. The Natural Toothbrush "Miswak" And The Oral Health. 2014.

26. Buadu CY, Yodem AEB. The antibacterial activity of some Ghanian chewing sticks. 1973.

27. Rotimi VO, Mosadomi HA. The effect of crude extracts of nine African chewing sticks on oral anaerobes. J Med Microbiol 1987;23:55-60.

28. Al lafi $\mathrm{T}$, Ababneh $\mathrm{H}$. The effect of the extract of the miswak (chewing sticks) used in Jordan and the Middle East on oral bacteria. Int Dent J 1995;45:218-22.

29. al-Bagieh NH, Idowu A, Salako NO. Effect of aqueous extract of miswak on the in vitro growth of Candida albicans. Microbios 1994;80:107-13.

30. Ali H, Konig GM, Khalid SA, Wright AD, Kaminsky R. Evaluation of selected Sudanese medicinal plants for their in vitro activity against hemoflagellates, selected bacteria, HIV-1-RT and tyrosine kinase inhibitory, and for cytotoxicity. J Ethnopharmacol 2002;83:219-28.

31. Al-Bagieh $\mathrm{N}$, Almas K. In vitro antibacterial effects of aqueous and alcohol extracts of miswak (chewing sticks). 1997.

32. Almas K, Al-Lafi TR. The natural toothbrush. 1995: Geneva: World Health Organization, 19801998. p. 206-11.

33. Elvin-Lewis $M$. The therapeutic potential of plants used in dental folk medicine. Odonto-stomatologie tropicale $=$ Tropical dental journal 1982;5:107-17.

34. Almas K. The antimicrobial effects of extracts of Azadirachta indica (Neem) and Salvadora persica (Arak) chewing sticks. Indian J Dent Res 1999;10:23-6.

35. Lorenzi H dAMF. Plantas Medicinais no Brasil: Nativas e Exóticas. 2nd edition. Sao Paulo, Brazil: Instituto Plantarum de Estudos da Flora. 2002.

36. Herrera Herrera A, Franco Ospina L, Fang L, Diaz Caballero A. Susceptibility of Porphyromonas gingivalis and Streptococcus mutans to Antibacterial Effect from Mammea americana. Adv Pharmacol Sci 2014;2014:384815.

37. Naderi NJ, Niakan M, Kharazi Fard MJ, Zardi S. Antibacterial activity of Iranian green and black tea on streptococcus mutans: an in vitro study. J Dent (Tehran) 2011;8:55-9.
38. Yoshino K NY, Ikeya $H$, Sei $T$, Inoue $A$, Sano M, Tomita I. Antimicrobial activity of tea extracts on cariogenic bacterium (Streptococcus mutans). J Food Hyg Soc Japan 1996;37:104-8.

39. Linke HA, LeGeros RZ. Black tea extract and dental caries formation in hamsters. Int J Food Sci Nutr 2003;54:89-95.

40. Yasuda $\mathrm{H}$, Arakawa T. Deodorizing mechanism of (-)-epigallocatechin gallate against methyl mercaptan. Biosci Biotechnol Biochem 1995;59:1232-36.

41. Masami SS, Kim M, Yamamoto T. Inhibitory effects of green tea polyphenols on growth and cellular adherence of an oral bacterium, Porphyromonas gingivalis. 1996.

42. Saxer UP SA, Szabo SH. Effect of mouthwashing with tea tree oil on plaque and inflammation. Menghini G Schweiz Monatsschr Zahnmed 2003;113:985-96.

43. Takarada K, Kimizuka R, Takahashi N, Honma K, Okuda K, Kato T. A comparison of the antibacterial efficacies of essential oils against oral pathogens. Oral Microbiol Immunol 2004;19:61-4.

44. Carson CF, Hammer KA, Riley TV. Melaleuca alternifolia (Tea Tree) oil: a review of antimicrobial and other medicinal properties. Clin Microbiol Rev 2006;19:50-62.

45. Prashant GM, Chandu GN, Murulikrishna KS, Shafiulla MD. The effect of mango and neem extract on four organisms causing dental caries: Streptococcus mutans, Streptococcus salivavius, Streptococcus mitis, and Streptococcus sanguis: an in vitro study. Indian J Dent Res 2007;18:148.

46. Sidhu P. The antimicrobial activity of azardirachta indica, glycyrrhiza glabra, cinnamum zeylanicum, syzygium aromaticum, accacia nilotica on streptococcus mutans and enterococcus faecalisAn in vitro study. Editorial 5 Original Research 2011;23:18.

47. Prabhat A, Navneet CA. Evaluation of antimicrobial activity of six medicinal plants against dental pathogens. Report Opinion 2010;2:37-42.

48. Wolinsky LE, Mania S, Nachnani S, Ling S. The inhibiting effect of aqueous Azadirachta indica (Neem) extract upon bacterial properties influencing in vitro plaque formation. J Dent Res 1996;75:816-22. 
49. Rosaline H, Kandaswamy D, Gogulnath D, Rubin $M$. Influence of various herbal irrigants as a final rinse on the adherence of Enterococcus faecalis by fluorescence confocal laser scanning microscope. J Conserv Dent 2013;16:352-5.

50. Al-Bayati FA, Sulaiman KD. In vitro antimicrobial activity of Salvadora persica L. extracts against some isolated oral pathogens in Iraq. Turk J Biol 2008;32:57-62.

51. Noumi E, Snoussi M, Hajlaoui H, Valentin E, Bakhrouf A. Antifungal properties of Salvadora persica and Juglans regia L. extracts against oral Candida strains. Eur J Clin Microbiol Infect Dis 2010;29:81-8.

52. Okubo S, Toda M, Hara $Y$, Shimamura $T$. [Antifungal and fungicidal activities of tea extract and catechin against Trichophyton]. Kansenshogaku Zasshi 1991;46:509-14.

53. Toyoshima Y, Okubo S, Toda M, Hara Y, Shimamura T. [Effect of catechin on the ultrastructure of Trichophyton mentagrophytes]. Kansenshogaku Zasshi 1994;68:295-303.

54. Park BJ, Park JC, Taguchi H, Fukushima K, Hyon $\mathrm{SH}$, Takatori K. Antifungal susceptibility of epigallocatechin 3-O-gallate (EGCg) on clinical isolates of pathogenic yeasts. Biochem Biophys Res Commun 2006;347:401-5.

55. Evensen NA, Braun PC. The effects of tea polyphenols on Candida albicans: inhibition of biofilm formation and proteasome inactivation. Can J Microbiol 2009;55:1033-9.

56. Shao X, Cheng S, Wang H, Yu D, Mungai C. The possible mechanism of antifungal action of tea tree oil on Botrytis cinerea. J Appl Microbiol 2013;114:1642-9.

57. Terzi V, Morcia C, Faccioli P, Vale G, Tacconi G, Malnati M. In vitro antifungal activity of the tea tree (Melaleuca alternifolia) essential oil and its major components against plant pathogens. Lett Appl Microbiol 2007;44:613-8.

58. Straede A, Corran A, Bundy J, Heinisch JJ. The effect of tea tree oil and antifungal agents on a reporter for yeast cell integrity signalling. Yeast 2007;24:321-34.
59. Polaquini SR, Svidzinski TI, Kemmelmeier C, Gasparetto A. Effect of aqueous extract from Neem (Azadirachta indica A. Juss) on hydrophobicity, biofilm formation and adhesion in composite resin by Candida albicans. Arch Oral Biol 2006;51:48290.

60. Nayak A, Nayak RN, Soumya B, Bhat K, Kudalkar M. Evaluation of antibacterial and anticandidal efficacy of aqueous and alcoholic extract of neem (Azadirachta indica): An in vitro study. IJRAP 2011;2:230-5.

61. Mahmoud DA, Hassanein NM, Youssef KA, Zeid A. Antifungal activity of different neem leaf extracts and the nimonol against some important human pathogens. Braz J Microbiol 2011;42:1007-16.

\section{Yazışma Adresi}

Prof.Dr. Ertuğrul ERCAN

Kırıkkale Üniversitesi Diş Hekimliği Fakültesi Restoratif Diş Tedavisi Anabilim Dalı

71200 Kırıkkale - Türkiye

Tel: 03182244927

Faks: 03182250685

e-mail: ertugrul@kırıkkale.edu.tr 